Adriana Yeraldinn Fandiño Castro *

\title{
Imaginarios urbanos en los niños de la ciudad de Chiquinquirá ${ }^{1}$
}

\section{Urban imaginaries in children of Chiquinquirá city}

Cómo citar:

Fandiño, A. (2018). Imaginarios Urbanos en los niños de la Ciudad de Chiquinquirá. Designia, 5(2), 81-99.

${ }^{1}$ Este artículo se deriva del macroproyecto “Cultura y estética popular en Boyacá", realizado por el grupo de investigación

Xisqua de la Universidad de Boyacá

* Arquitecta egresada de la Universidad de Boyacá. adrianaf4nc@gmail.com orcid.org/0000-0002-4422-1062
Palabras clave:

Imaginario urbano, niños,

Chiquinquirá, cultura, percepción, religión.

Key words:

Urban imaginary, children, Chiquinquirá, culture, perception, religion.

Recibido: 03/10/2017

Aceptado: 13/06/2018

\section{Resumen:}

El presente artículo de investigación se deriva de un estudio de imaginarios urbanos que hace parte del macroproyecto "Cultura y estética popular en Boyacá", el cual indaga en torno a los imaginarios urbanos en el departamento de Boyacá con el fin de conocer la construcción de la imagen del lugar en diferentes ciudades. En este caso específico se valoró el sentido común a partir de los conocimientos de un grupo poblacional joven, capaz de ofrecer un concepto real y veraz de ciudad. Se buscó definir el imaginario que actualmente tienen los niños de Chiquinquirá, con el objetivo de establecer la identidad de la ciudad a partir de tal imaginario e identificar los elementos clave que dan forma y materializan dichas percepciones, tanto individuales como grupales, más allá de indagar por qué se construye esa imagen de una manera u otra. Se consolidó una base teórica que abarcó temáticas relacionadas para fundamentar la investigación y guiar el ejercicio práctico 
en colegios con poblaciones similares a través de un proceso que incluyó herramientas como encuestas individuales con enfoque teórico-práctico, encuestas de información general y cartografías urbanas. Se incluyeron también mapeos colectivos que aplicados al caso de estudio facilitaron la objetividad investigativa. Los resultados se agrupan en tres ámbitos (percepciones, cultura y espacialidad) con los que se espera ilustrar acerca de la lectura espacial de la ciudad.

\section{Abstract:}

This research paper, derived from research on urban imaginaries, pertains to the macro-project Culture and popular aesthetics in Boyacá, which is conducted by the Universidad de Boyacá's Xisqua research group. The project explores urban imaginaries in the Boyacá province in order to inquire about the construction of the image of place in different cities. In this particular case study, the knowledge and opinions by a young population group which is deemed as capable of providing an accurate concept on the city were valued. Beyond analyzing why the city image is constructed in one way or another, it was intended to define the present imaginary of Chiquinquirá's children concerning the place they live in, identifying at the same time both the town's identity based on such an imaginary and the key elements shaping and materializing the children's individual and group views. A theoretical basis including interlinked topics was considered to ground the study and guiding the practical process in akin-population schools. This process was carried out by employing research tools such as individual theoretical-practical surveys, general information surveys, and urban cartography. Collective mapping was also applied to strengthen the case study's objectivity. The results grouped into three main areas (perceptions, culture, and spatiality) are expected to offer insight into the city spatial reading. 


\section{INTRODUCCIÓN}

Los seres humanos crean imaginarios del espacio donde habitan, ya sean individuales o colectivos, para desenvolverse en los entornos con los que se relacionan. En las ciudades se crean mapas a partir de las imágenes formadas por cada persona de acuerdo con sus vivencias, recorridos y rutinas. Al sumarse estos conocimientos es posible concebir un concepto general de la ciudad y unas ideas específicas de distintos lugares. Una lectura de imaginarios de ciudad es necesaria ya que gracias a esta se puede conocer una determinada identidad urbana a partir de las imágenes elaboradas por sus habitantes mediante sus vivencias de los lugares que visitan de manera individual o grupal, las cuales, eventualmente, generan ideas globales de un sitio.

La Virgen del Rosario de Chiquinquirá fue resaltada como “ ¡Reina de nuestra patria y reina del mundo y las edades!" por el expresidente colombiano Marco Fidel Suárez, según lo refiere Botero (2008), quien evidencia la importancia de la imagen como símbolo de identidad para la nación colombiana mediante la rememoración anual de la leyenda asociada a dicha figura. A partir de esta referencia cabe preguntar si Chiquinquirá aún mantiene el imaginario de ciudad religiosa para sus habitantes o si tal percepción se ha transformado y de ser así, cuál(es) planteamiento(s) nuevo(s) de ciudad ha adquirido y qué ha influenciado las posibles variaciones.

\section{METODOLOGÍA}

Para dar respuesta a este interrogante y establecer la identidad de la ciudad entre la población infantil en particular, se formuló la siguiente pregunta investigativa: ¿cuál es la identidad de Chiquinquirá según los imaginarios de los niños? Se definió una muestra de niños entre 11 y 12 años de colegios públicos y privados distribuidos en la ciudad con el fin de identificar relaciones espaciales de lugares frecuentados; distinguir actividades, actores y sectores relevantes; y puntualizar las relaciones espaciales con mayor valoración. Al resolver estas categorías de análisis se apuntó a representar el imaginario de ciudad y generar una propuesta espacial con la información obtenida.

Los referentes conceptuales consultados para el desarrollo de la investigación se clasifican en dos temáticas. Por una parte, los imaginarios urbanos expuestos por Silva (2006), quien estudió imaginarios en Latinoamérica y abarcó esta temática desde un enfoque social que permite realizar aproximaciones al reconocimiento del lugar desde los sentidos (olfato, gusto, tacto, oído) y las imágenes del entorno. Por otro lado, la 
lectura espacial propuesta por Lynch (1960), quien determinó elementos comunes de identificación en la ciudad, tales como nodos, mojones, hitos, sendas y bordes a partir de las percepciones de quienes recorren el espacio urbano e identifican dichos elementos. A su vez, estas temáticas son relacionadas por González (2004) en un estudio de percepción y cognición muy asociado con los dos autores mencionados y efectuado entre una población infantil específica en un colegio de Bogotá.

Respecto a los imaginarios es pertinente comentar que estos implican no solo cuanto percibimos sino también lo que esperamos que sea, es decir, nuestros ideales de ciudad. Sin embargo, no basta con pretender que la ciudad "sea" si quienes la construyen lo hacen enfocados en sus intereses personales -como es costumbre-. Lograr espacios pensados para la gente precisa la incorporación de las expectativas de la comunidad en una dinámica cercana a la señalada por Battro y Ellis: "la ciudad es el 'lugar donde se aprende' y muchos educadores contemporáneos han comenzado a utilizar la ciudad como una verdadera prolongación de la escuela" (1999, p. 1).

Según Vega y García, los imaginarios sociales "legitiman poderes, establecen valores y modelan conductas. Sin embargo, no se puede suponer que todos tenemos los mismos imaginarios sociales" (2005, p. 5). Aunque en una primera aproximación son de carácter individual, los imaginarios se convierten en realidades sociales colectivas o compartidas por masas, lo cual conlleva a una tendencia a realizar acciones grupales, como ocurre con la legitimación del poder indicada por estos autores.

Los imaginarios pueden ser de corta duración al depender de procesos de captación y renovación de percepciones en entornos que cambian rápidamente (Martínez, 2011). Es necesaria entonces una lectura amplia de la ciudad para obtener conclusiones en una investigación con características de aproximación social a la realidad.

En relación con la muestra poblacional definida para el estudio, cabe señalar que los niños a través de su experiencia y formación expresaron sus interpretaciones de la ciudad. Dada la importancia de su aporte se definió una fase en que la información fue captada y expresada de manera formal, teniendo en cuenta lo planteado por Piaget y mencionado por Meece (2000): “todos, incluso los niños, comienzan a organizar el conocimiento del mundo en lo que [Piaget] llamó esquemas. Los esquemas son conjuntos de acciones físicas, de operaciones mentales, de conceptos o teorías con los cuales organizamos y adquirimos información sobre el mundo." (p. 102). Ciertamente, no hay una limitación que sesgue la pertinencia de la información de este grupo poblacional, más allá de condicionantes hacia ciertos grupos que por ideas preexistentes dejan de contar o ser relevantes en la construcción de ciudad. 
Piaget fue uno de los teóricos que estudió el desarrollo cognoscitivo e identificó cuatro etapas: sensoriomotora, que comprende desde el nacimiento hasta los dos años; preoperacional, de los dos a los siete años; operaciones concretas, de los siete a los once; y operaciones formales, entre los once y los doce. Esta última fue la mejor valorada para abordar la muestra investigativa pues se caracteriza de esta manera:

La capacidad de pensar en forma abstracta y reflexiva se logra durante la etapa de las operaciones formales (...) cuatro características fundamentales de este tipo de pensamiento: la lógica proposición, el razonamiento científico, el razonamiento combinatorio y el razonamiento sobre probabilidades y proporciones. Se da el nombre de operaciones formales a la capacidad de pensar en forma abstracta y razonar (...) La lógica proposicional es la capacidad de extraer una inferencia lógica a partir de la relación entre afirmaciones o premisas (Meece, 2000, p. 114).

Fue pertinente abarcar esta última etapa, caracterizada por el desarrollo de un razonamiento abstracto y razonable, carente de prejuicios y verdades absolutas. Así, se buscó lograr la lectura del entorno desde la perspectiva infantil y aportar objetividad a la investigación. Siguiendo estos parámetros se seleccionaron grupos de séptimo grado en seis colegios de Chiquinquirá, tanto públicos como privados. Dos grupos pertenecían al sur, dos al centro y dos al norte de la ciudad, en aras de obtener una lectura urbana general. Fueron considerados tres ámbitos de análisis:

1. Percepciones: relacionadas directamente con las representaciones materializadas individual y colectivamente que sirven como refuerzo en la construcción del imaginario.

2. Cultura: interpretada a través del reconocimiento y la apropiación de elementos, lugares y/o personajes representativos de la ciudad que han merecido un énfasis en su mención o conmemoración durante el tiempo.

3. Espacialidad: enfocada en la imagen de la ciudad a través de mapeos. Se exploró grupalmente (a diferencia de los ámbitos previos que fueron individuales) para lograr imágenes completas e identificar percepciones en espacios similares. 
La investigación se realizó en cinco fases:

1. Exploratoria. Consolidación de la base teórica investigativa. La recopilación y revisión de otros proyectos permitió delimitar y guiar el desarrollo práctico del presente.

2. Construcción de herramientas. Se estructuró un cuestionario personal con preguntas abiertas y de opción múltiple, como también un componente práctico para la identificación espacial en la ciudad que apuntó a identificar lugares, actores y frecuencias de uso. Se realizó un ejercicio grupal de mapeo que permitió reconocer espacios representativos, actividades, actores y sectores, además de las relaciones espaciales y las percepciones generadas por estos elementos.

3. Aplicación de instrumentos. En esta fase se formuló una lectura general de la ciudad.

4. Análisis e interpretación. La información obtenida requirió análisis tanto cuantitativo como cualitativo para llegar a conclusiones rigurosas acerca del caso de estudio.

5. Síntesis y conclusiones. Los temas que evidenciaron mayor relevancia al sintetizar la información se relacionaron con la hipótesis primaria de la ciudad religiosa. Si bien no se reveló el énfasis esperado, fue posible formular nuevos planteamientos.

\section{RESULTADOS}

Los siguientes resultados relacionan las tendencias encontradas en los ámbitos de análisis descritos previamente. Debe tenerse en cuenta la dimensión de la información obtenida de la muestra total (120 encuestas individuales y seis mapeos grupales).

\section{Percepciones}

A continuación, se describen los resultados derivados de las relaciones espaciales más valoradas, según las imágenes urbanas que los niños han formado de su entorno. 


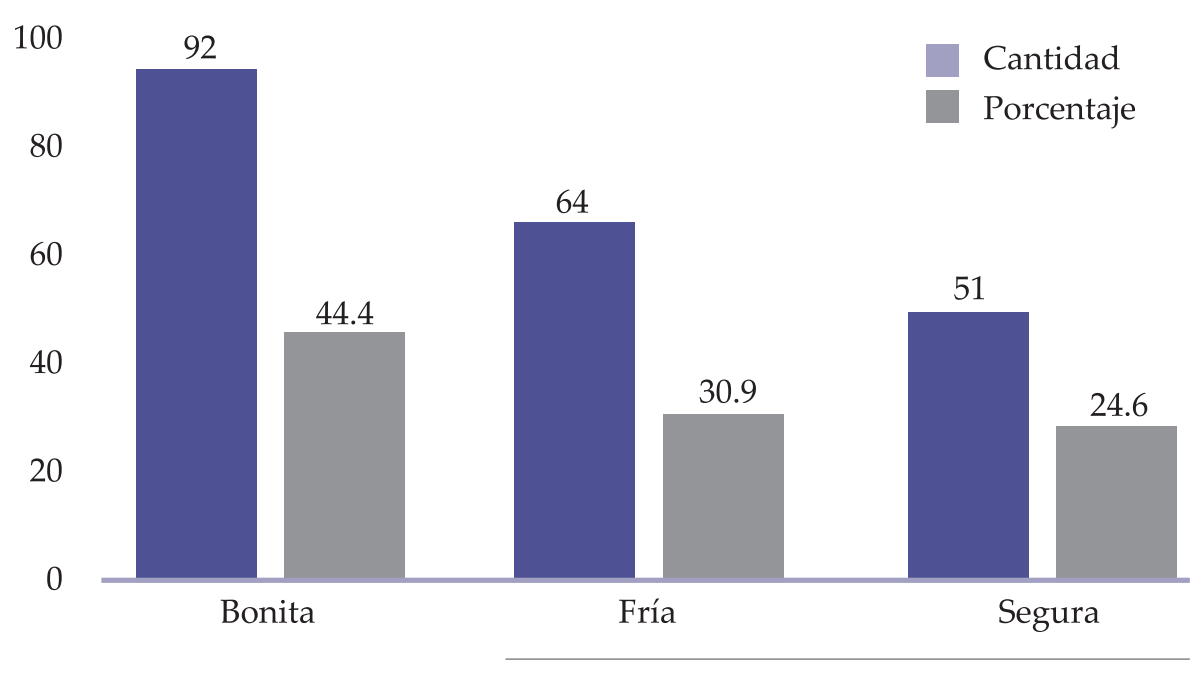

Figura 1. Dimensiones y características de ciudad. Fuente: autor.

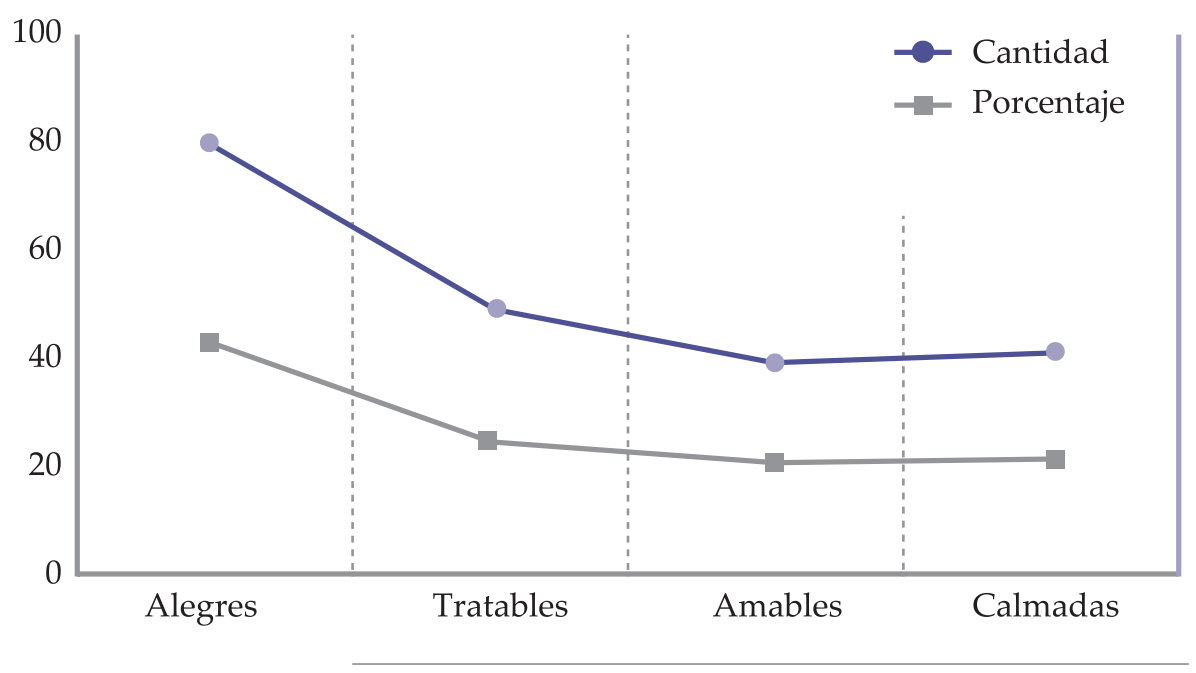

Figura 2. Percepción de las personas con que se relaciona.

Fuente: autor.

En lo referido a las percepciones hay una relación proporcional entre las características de la ciudad y las personas que la habitan, como se indica en los gráficos de las figuras 1 y 2 . De acuerdo con los resultados generales y específicos por colegios y sectores, los niños asocian por igual la ciudad bonita y segura con personas alegres y tratables; en menor medida, la ciudad insegura se vincula con personas tristes y hoscas. 


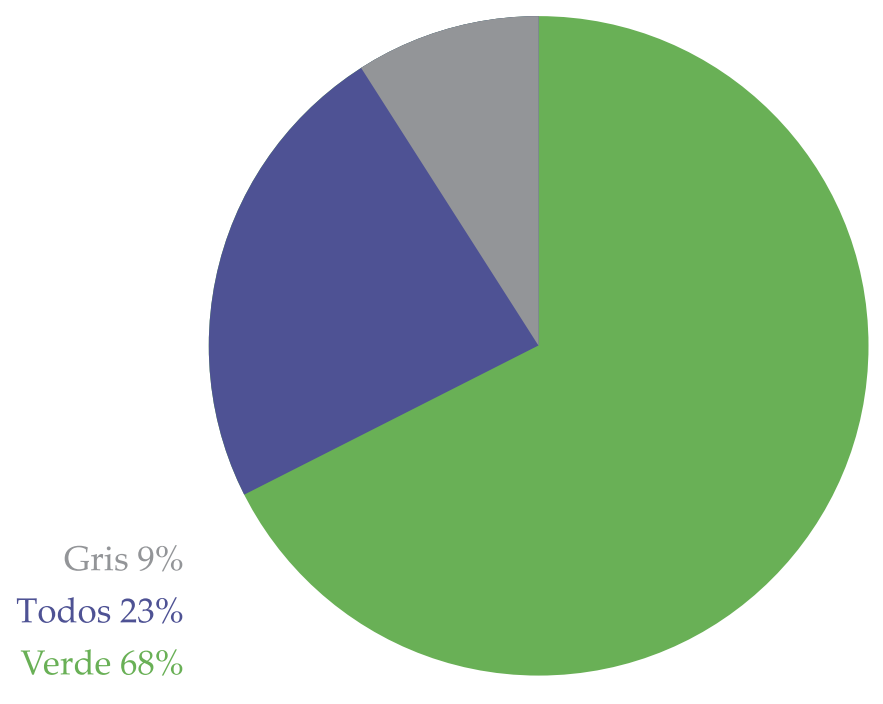

Figura 3. Un color que identifique la ciudad.

Fuente: autor.

El color (figura 3) es entendido como el reflejo o la expresión de una cultura que ha sido construida a partir de las expresiones espaciales, las variaciones durante el tiempo y el anhelo de futuros cambios (Rodríguez, 2013). Aunque en la investigación se manifestaron diferentes colores, el verde fue un común denominador en cuanto a las percepciones espaciales, las proyecciones y los imaginarios, lo cual puede relacionarse con los lugares frecuentados (espacios públicos, zonas verdes) y las percepciones futuras ("más parques"). Este color se entiende entonces en términos espaciales y de reconocimiento de lugares dentro de la ciudad.

Estos imaginarios percibidos mediante colectivos reflejan actividades sociales que dan paso a ideolectos y permiten la interacción de culturas distintas en un mismo territorio (Nieto, 2011). Los imaginarios, en un principio individuales, pueden conducir a una apropiación de la cultura que se manifiesta en expresiones y deseos de aportar elementos que buscan mejorar las vivencias colectivas. 


\section{Cultura}

Estos resultados se refieren a las actividades, los actores y sectores importantes de la ciudad según los imaginarios de los niños

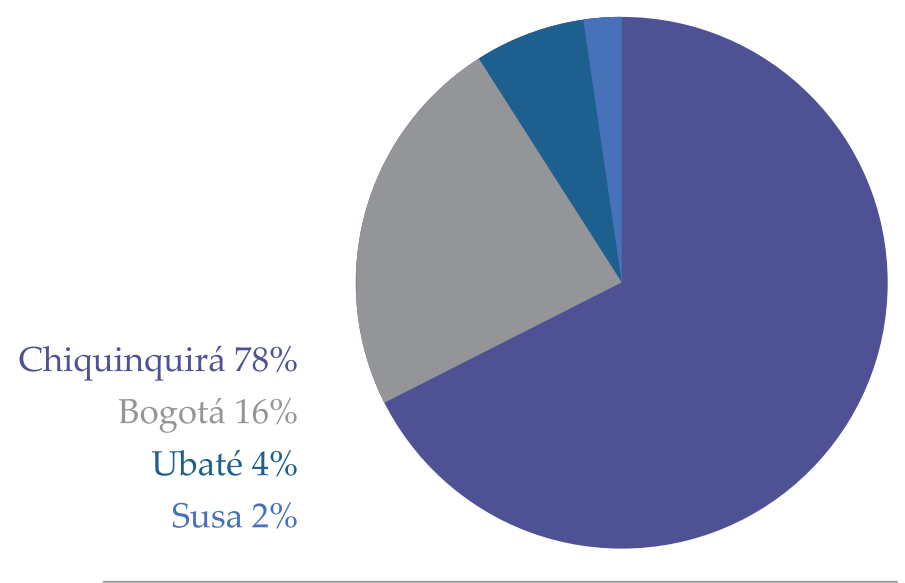

Figura 4. Procedencia de los niños residentes en la ciudad.

Fuente: autor.

La figura 5 muestra la percepción espacial general de Chiquinquirá como ciudad o municipio con base en la interpretación que los niños hacen de su entorno directo y cuánto han vivido en él. Además, indica un acercamiento hacia la cercanía con el lugar.

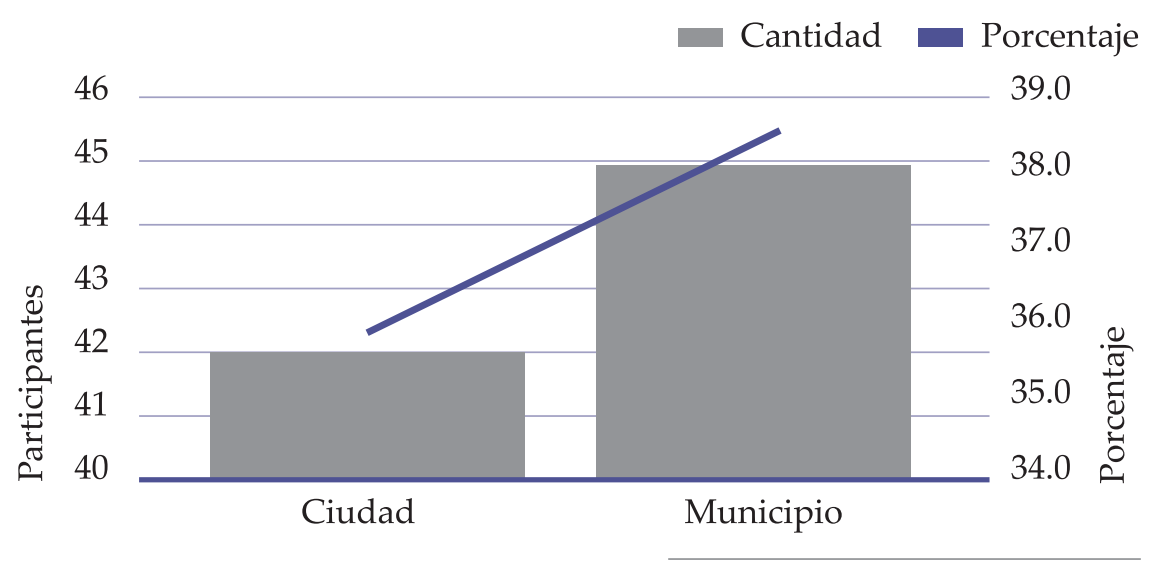

Figura 5. Dimensión del lugar. Fuente: autor. 
El análisis de las cartografías e imágenes de identificación reflejó que además de los elementos positivos con que se representa la ciudad existen caracterizaciones de miedos e inseguridades. Hienaux (2007) señala estas expresiones como recurrentes y en aumento en estudios urbanos recientes, siendo el miedo al otro la manifestación principal. A partir de este reconocimiento se identificaron lugares de incidencia y se encontraron, principalmente, patrones asociados a espacios abandonados y alejados. Esto puede ser útil en la búsqueda de soluciones a determinadas problemáticas.

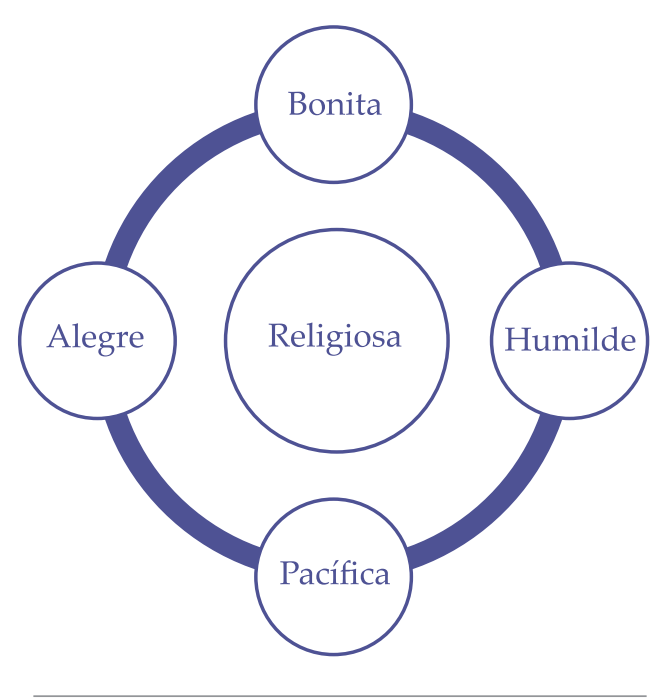

Figura 6. Una palabra que describa la ciudad. Fuente: autor.

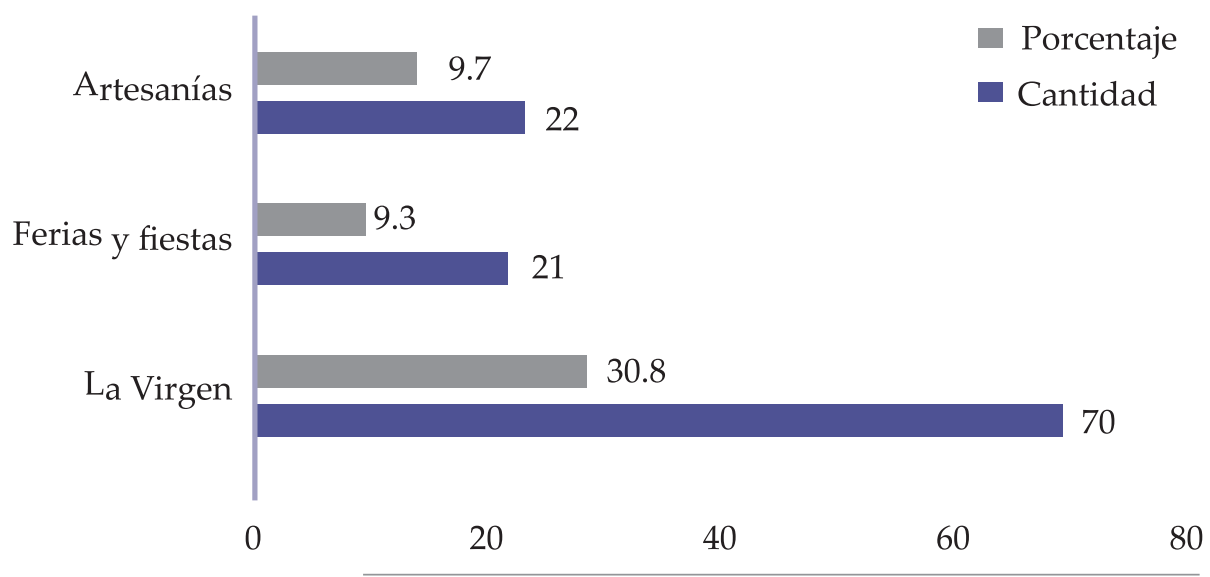

Figura 7. Aspecto relevante para la ciudad. Fuente: autor. 
Con base en las respuestas representadas en las figuras 6 y 7 se puede afirmar que Chiquinquirá tiene un marcado imaginario religioso representado en la imagen de la Virgen y reforzado a través de las iglesias extendidas a lo largo de la ciudad. Este aspecto es indiferente de la religión pues la devoción y el apego por el imaginario es similar sin importar el credo que se profese o el lugar donde sea compartido.

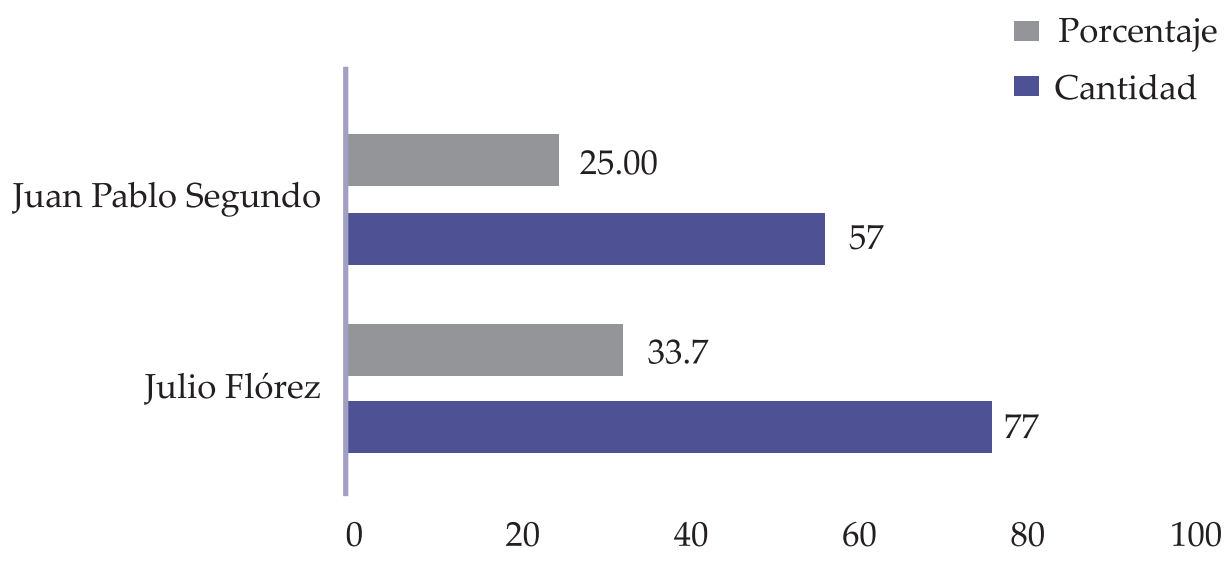

Figura 8. Un personaje.

En cuanto a personajes, existen dentro del área urbana lugares nombrados para rememorar la memoria de figuras representativas para la ciudad. Julio Flórez y Juan Pablo Segundo fueron los más recordados pues prácticamente obtuvieron la totalidad de identificaciones, como se aprecia en la figura 8. Los espacios que llevan sus nombres tienen en común que son públicos, el segundo con horarios establecidos por la población que lo utiliza. Se trata de parques al aire libre donde acuden numerosas personas para disfrutar de los servicios ofrecidos. Estos lugares han sido referencia histórica para diferentes generaciones, quienes encuentran allí parte de sus memorias y su cultura. Asimismo, en consonancia con la descripción de Bazant (2008), son escenarios para la convivencia con otros en procesos de aprendizaje. 

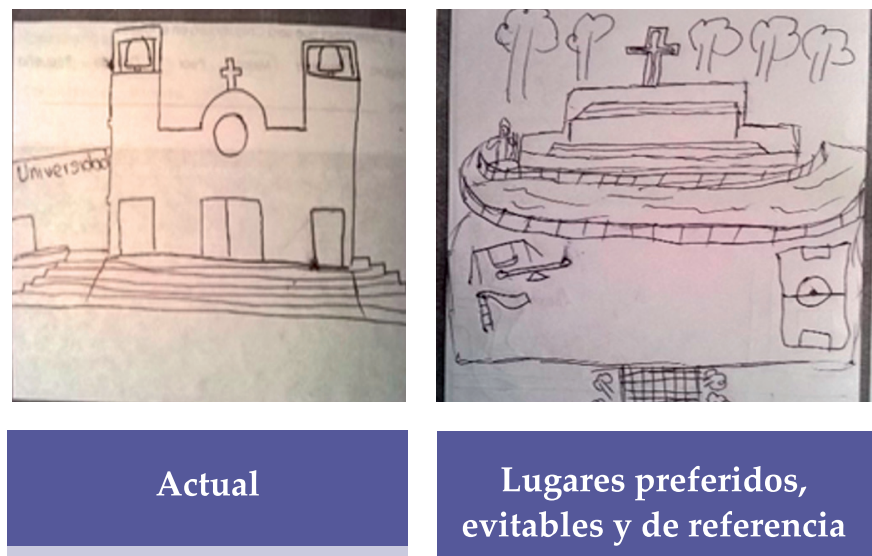

Basílica

- Representación planimétrica general de ciudad

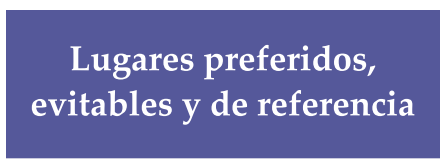

- Parque Juan Pablo II

- Parque Julio Flórez

- Plaza de mercado

- Terminal de transporte

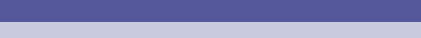

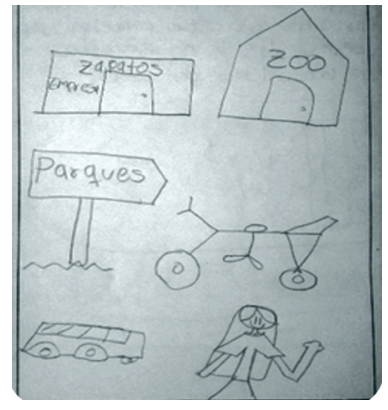

\section{Elementos} representativos en proyecciones gráficas

- Comunicaciones

- Espacios públicos parques

- Edificaciones

Figura 9. Resumen de cartografías individuales. Fuente: autor.

La información de las encuestas también permitió delinear la lectura cartográfica de la ciudad que se esquematiza en la figura 9. Esta lectura comienza por determinar elementos comunes para comprender la formación de un pensamiento generalizado. Como lo describe Pérgolis (2000), se inicia con hechos aislados y se culmina con un pensamiento elaborado en el cual se define una visión del territorio que va más allá del espacio físico y se relaciona con la historia de las mentalidades. De tal modo se aporta en la formación de cultura gracias a una participación ciudadana que puede contribuir a la búsqueda de soluciones y aportar al conocimiento común. 


\section{Espacialidad}

Respecto a la configuración urbana se encontró cierta idealización. Se piensa que el asentamiento fue formándose en medio de dos cerros a partir del milagro de la renovación del cuadro de la Virgen del Rosario de Chiquinquirá. Como explica Barrera: "El mito, la fe y el sentimiento religioso transformaron un espacio vacío y sacralizado en espacio real, óptimo para la convivencia humana" (2011, p. 82). Ese espacio se conformó linealmente, definido por sus vías, alrededor de las cuales se distribuyeron paulatinamente diferentes sitios de referencia que han servido para establecer un denominador común en la interpretación y la identificación urbana.

Para identificar aquellos imaginarios urbanos que se establecen mediante las relaciones espaciales se definió una lectura general de la ciudad religiosa a través de tres ámbitos generales. Primero, el actual, en el que la mayoría de encuestados reconoció la Plaza de la Libertad y la Basílica allí situada como lugares representativos o que definen a Chiquinquirá. Segundo, los lugares preferidos y evitables. Tercero, los recorridos o elementos que sirven como referencia de ubicación. Los parques ocuparon la primera posición entre los sitios de preferencia, seguidos por espacios comerciales bajo la condición de "evitables" (lo cual se relacionó en algunos casos con sus olores, imagen y asepsia). A su vez, espacios de uso dotacional y vías usadas con mayor frecuencia, especialmente en el centro, fueron destacadas como referencias. 
COLEGIOS PRIVADOS SECTOR SUR - CENTRO - NORTE
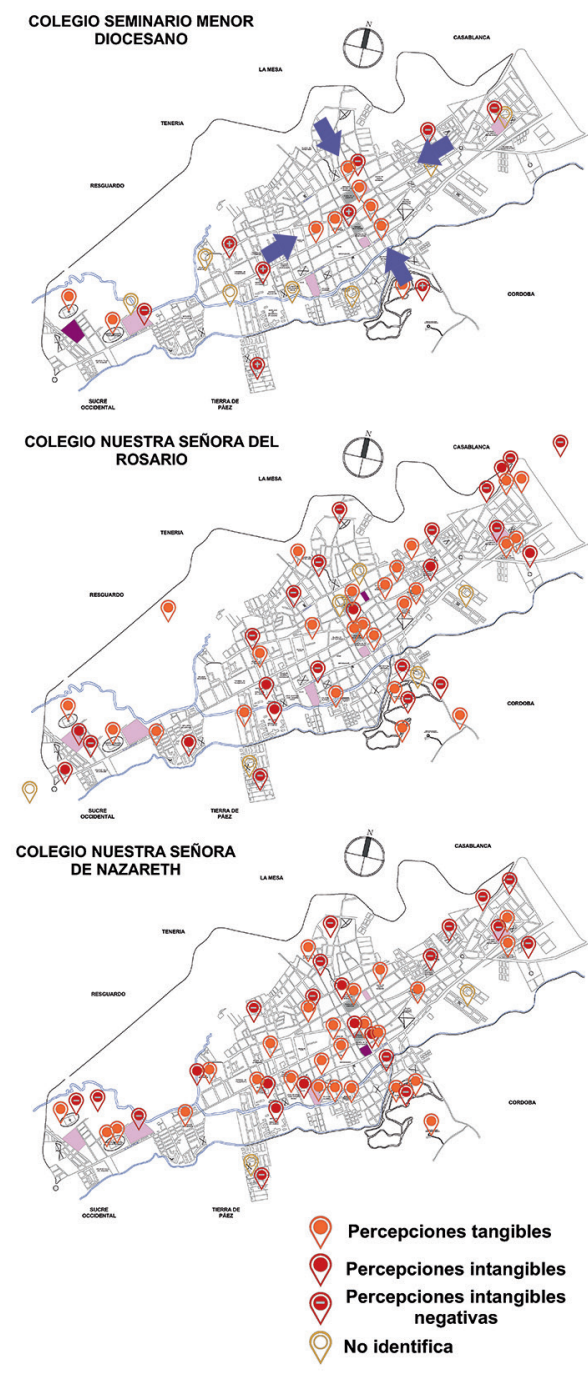

COLEGIOS PÚBLICOS SECTOR SUR - CENTRO - NORTE

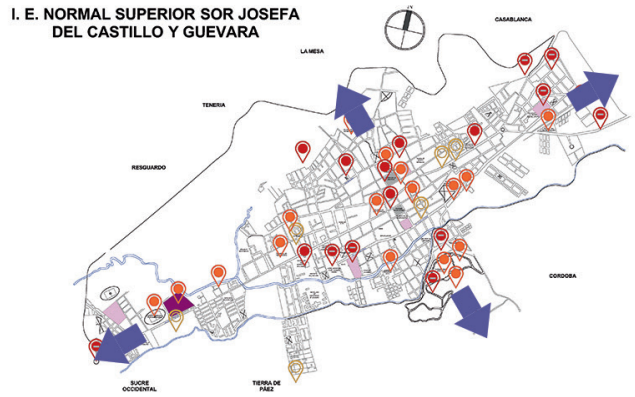

I. E. TECNICO INDUSTRIAL JÚLIO

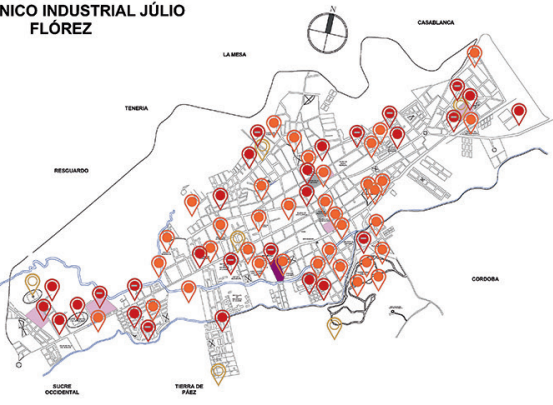

I. E. PIO ALBERTO FERRO PENA

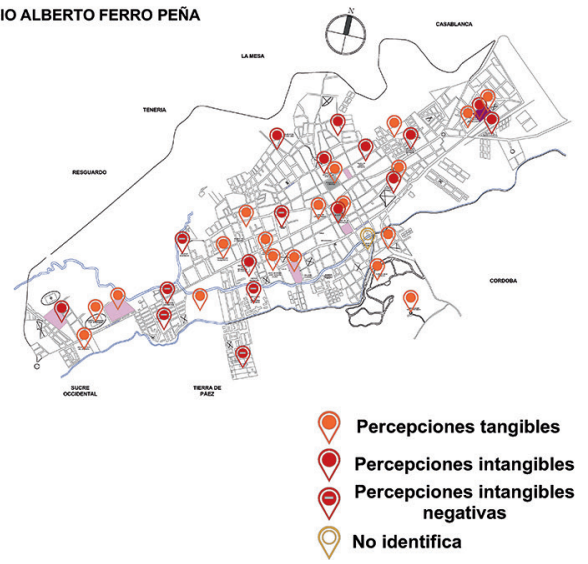

Figura 10. Comparación del resultado de mapeos. Fuente: autor. 
En los mapeos realizados, con frecuencia se presenta que en los colegios privados la lectura de ciudad es más "cerrada" o se limita a recorridos específicos que influyen en un reconocimiento espacial escaso. Por el contrario, en los colegios públicos hay mayor apropiación de recorridos y lugares, de modo que se construye un mapa con menos vacíos y la interpretación urbana involucra más espacios asociados con distintas emociones (en la figura 10 se esquematizan estas interpretaciones). Sucede, como comenta Carreiras: "a medida que nuestro espacio de actividad se expande exploramos más lugares, que representamos en relación a los que previamente conocíamos. Organizamos el mapa cognitivo según una jerarquía funcional de lugares" (1986, p. 6). Puede entenderse así la razón por la que unos colegios tienden a cerrarse o abrirse en relación con la ciudad, pues su conocimiento y valoración del espacio urbano difiere de acuerdo con los sitios frecuentados por sus estudiantes.

\section{Hacer mapas sirve para agilizar el trabajo y la reflexión colectiva a la hora de pensar nuestro territorio. Un mapa nos brinda la posibilidad de tomar distancia, de imaginar un vuelo de pájaro que nos facilite descifrar las cone- xiones entre las diversas problemáticas a fin de cuestionarlas y elaborar alternativas de resistencia, organización y cambio. (Iconoclasistas, s.f., p. 3).}

Este planteamiento, propuesto en un proyecto desarrollado por Iconoclasistas, sirvió de referencia para determinar la utilización de mapas como recurso de identificación en la recolección de información. Asimismo, por medio de mapas se llegó a conclusiones acerca de lecturas espaciales de la ciudad desde sus miradas positivas, negativas, de percepción espacial y de proyección hacia mejoras, en las cuales se evidencian carencias, anhelos y deseos de cambio. 


\section{PRODUCTO}

Finalmente, con base en los resultados del estudio y con el objetivo de representar el imaginario de ciudad, se ha planteado un módulo itinerante y replicable que busca dar a conocer los vacíos urbanos considerados como espacios negativos; fortalecer la identificación de lugares que gozan de aceptación y de aquellos que pueden tenerla pero no son evidentes; como también incentivar el conocimiento de la ciudad, pues tal parece que es limitado. Una propuesta para el módulo se presenta en la figura 11.

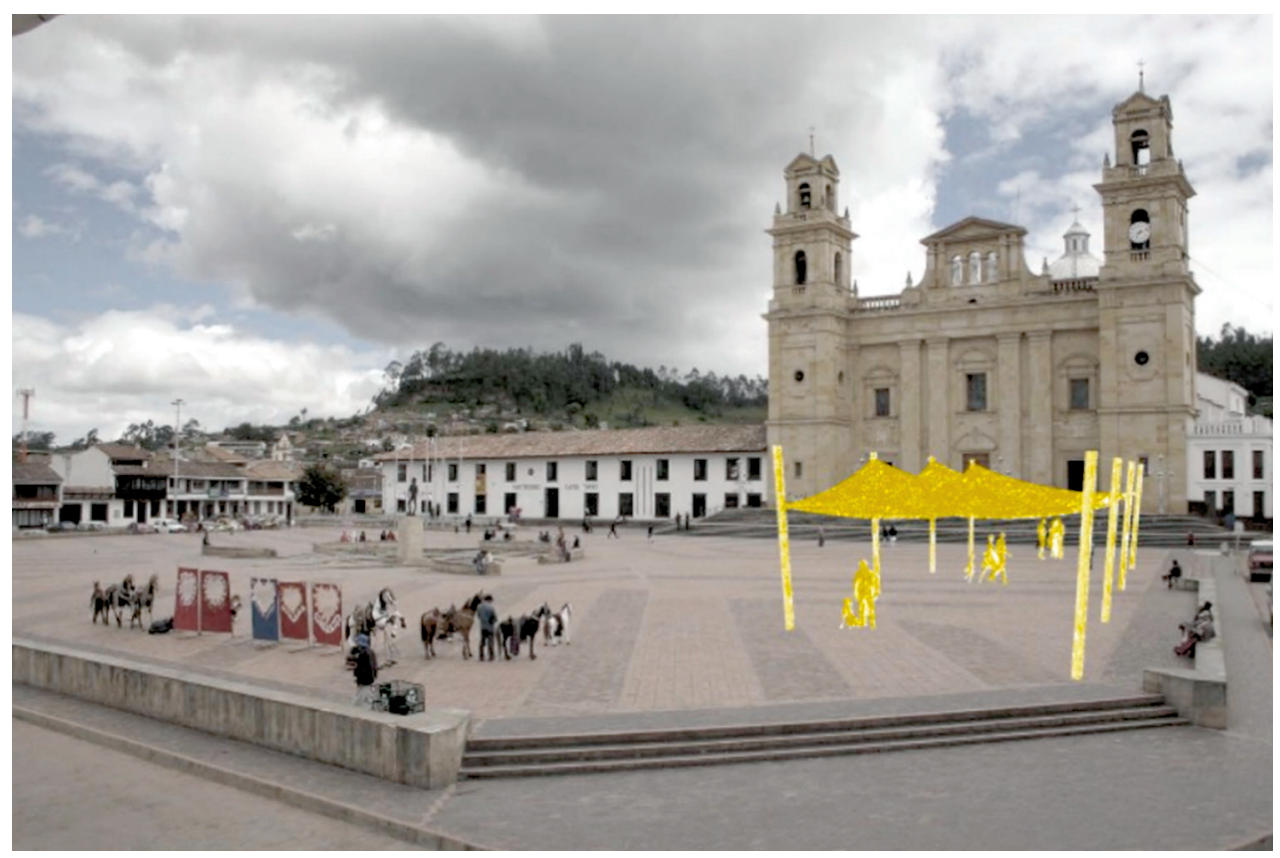

Figura 11. Módulo itinerante.

Fuente: autora, sobre una imagen obtenida de http://www.tripmondo.com/colombia/boyacá/el-molino

Para plantear este módulo se han indagado referentes en proyectos como "Esto no es un solar/Grávalos di Monte - Zaragoza” y "La casa ensamble Chacarrá - Pereira”, entre otros, cuyos resultados han sido destacados en su relación con las comunidades. 


\section{CONCLUSIONES}

Los imaginarios de Chiquinquirá han sido formulados en torno a la religiosidad y las ceremonias que las creencias religiosas evocan. Es marcada y evidente la importancia que para el desarrollo de la ciudad ha tenido este aspecto y su continuidad a través de peregrinajes y actos religiosos solemnes, sin que se enmarque en una sola religión.

La cultura, las percepciones y la espacialidad identificada por los niños de los colegios de Chiquinquirá lleva a concluir que, en general, la ciudad es vista como un lugar religioso, lo cual se evidencia en sus ritos y se refuerza por las edificaciones destinadas a estas prácticas, construcciones que son ampliamente relacionadas. En cambio, la información acerca de otros lugares se limita a un vago reconocimiento histórico de elementos representativos diferentes a los religiosos. Por su parte, en la lectura espacial todos los encuestados identificaron varios sitios comunes, así como la linealidad de la ciudad y la importancia del centro para su vida urbana.

Es importante resaltar la proyección general de ciudad "verde" como un ideal. Hay expectativas por más espacios al aire libre, en particular parques y zonas de recreación o interacción, y se enfatiza en el valor de los existentes. Asimismo, se piensa en una ciudad más grande, con mejor infraestructura y conectividad, en donde sea posible ampliar el imaginario urbano no solo como espacio sino también como cultura. 
Los imaginarios son positivos y negativos. Así, al reconocer la ciudad, los lugares en su mayoría agradables también son percibidos como inseguros. En el reconocimiento de espacios urbanos se definen dos relaciones: por una parte, conocimiento-jerarquización espacial, y por otra, desconocimiento-desconfianza e inseguridad.

El módulo itinerante como respuesta a la representación de imaginario de ciudad es planteado como un recurso para socializar la información ante la comunidad. Cabe resaltar la pertinencia de una nueva revisión de imaginarios dentro de un tiempo prudencial para comprender la evolución del imaginario y de la relación ciudadano-ciudad, al igual que para ampliar el conocimiento general acerca del imaginario urbano.

\section{REFERENCIAS BIBLIOGRÁFICAS}

Barrera, N. P. (2011). Historia de Chiquinquirá. Bogotá: Centro Don Bosco.

Battro, E., \& Ellis, A. (1999). La imagen de la ciudad en los niños. Obtenido de http://www.byd.com.ar/ ciudad10.htm

Bazant, J. (2008). Espacios urbanos. Historia. Teoria y diseño. (B. 95, Ed.) Mexico D.F.: Limusa S.A.

Botero, R. L. (2008). La virgen de Chiquinquirá: símbolo de identidad nacional. Revista colombiana de sociología( $\left.\mathrm{N}^{\circ} 31\right), 83-94$.

Carreiras, M. (1986). Mapas cognitivos: Revisión crítica. Estudios de psicología(26), 61-91.

González, P. (2004). Imágenes de ciudad percepción y cognición en niños de Bogotá. Bogotá: Alcaldia Mayor de Bogotá. Instituto Distrital de Cultura y Turismo - Observatorio de Cultura Urbana. 
Hiernaux, D. (Agosto de 2007). Los imaginarios urbanos: de la teoría y los aterrizajes en los estudios urbanos. Eure, XXXIII(99), 17-30.

Iconoclasistas. (s.f.). Mapeo colectivo profundizando la mirada sobre el territorio. Obtenido de iconoclasistas: www.iconoclasistas.com.ar

Lynch, K. (1960). La imagen de la ciudad. Barcelona: Gustavo Gili, SL, Barcelona, 1984, 1998.

Martinez, J. (27 y 28 de Enero de 2011). Cultura visual e imaginarios juveniles: una investigacion narrativa. I Jornadas "Investigar con los jóvenes: cuestiones temáticas, metodológicas, éticas y educativas". Universidad de Barcelona, Barcelona.

Meece, J. (2000). Teoría del desarrollo cognositivo de Piaget. (S. d. pública, Ed.) Compendio para educadores, $101-127$.

Nieto, S. Y. (2011). Cuando el lugar es solo el imaginario: Morcá. Designia, 1(1), 67 - 85. 